\title{
Sedation and Pain Management in Acute Neurological Disease
}

\author{
Marek A. Mirski, M.D., Ph.D., ${ }^{1}$ and John J. Lewin III, Pharm.D., BCPS ${ }^{2}$
}

\section{ABSTRACT}

The optimum provision of pharmacological sedation of the critically ill neurological patient requires defining the underlying etiology of agitation or need for sedation to determine the optimal agent: pain management, anxiolysis, or treatment of delirium. An appropriate regimen can then be decided upon based on the profiles of action of the several common classes of sedative agents. Methods to both evaluate the efficacy of sedation as well as titration to a predefined clinical goal are important tools toward safe administration of drugs that often have serious adverse effects. Recognition of an individualized approach is also necessary as patients will vary considerably with respect to the kinetics and pharmacodynamics of sedative therapy. The drug classes often selected for sedation in an intensive care unit will be reviewed as well as the metrics by which physicians can achieve their objectives in a safe manner.

KEYWORDS: Sedation, scales, pharmacokinetics, intensive care unit, toxicity

The intensive care unit (ICU) represents a unique acute management arena for neurologically compromised patients. Of particular concern is the desire or perceived need for patients to receive pharmacotherapy for the control of pain or to provide sedation as a means to reduce the signs and symptoms of pain, anxiety/stress, agitation, and delirium. Additionally, the use of benzodiazepines and other amnestic agents are often administered to eliminate recollection of particularly psychologically stressful periods.

Historically, ICU care plans often placed the management of pain and stress on a lower tier of importance, or purposefully administered high doses of medication to render the patient unresponsive. ${ }^{1}$ More recent advances in ICU management have put more of an emphasis on the goal of attaining an awake, yet comfortable patient. As of 2000, the Joint Commission on
Accreditation of Healthcare Organizations (JCAHO) introduced the mandate for the implementation of standards for pain assessment and treatment in hospitalized patients with the aforementioned objective. ${ }^{2}$ Coupled with more recent proposed standards toward ventilatory weaning and reducing ventilator-associated pneumonia, patient management in ICUs has evolved considerably. The emphasis has been on improved sedation and analgesia guidelines as well as minimizing the use of neuromuscular paralysis. Further spurring the interest in ICU sedation are studies documenting that routine assessment of nonparalyzed patients is instrumental in reducing ventilatory time, shortening overall ICU length of stay (LOS), and recognizing and preventing neurological deterioration. ${ }^{3,4}$

The reappraisal of analgesia and sedation for critically ill patients has been helpful in the evaluation
${ }^{1}$ Neurosciences Critical Care Unit/Neuroanesthesiology, The Johns Hopkins University, Baltimore, Maryland; ${ }^{2}$ Departments of Pharmacy Services and Anesthesiology and Critical Care Medicine, The Johns Hopkins Medical Institutions, Baltimore, Maryland.

Address for correspondence and reprint requests: Marek Mirski, M.D., Ph.D., Department of Anesthesiology and Critical Care Medicine, Division of Neuroanesthesia/Neurosciences Critical Care, The Johns Hopkins Hospital, 600 North Wolfe Street, Meyer 8-
140, Baltimore, MD 21287 (e-mail: mmirski@jhmi.edu).

Neurological Consultation in the ICU; Guest Editors, Romergryko

G. Geocadin, M.D., and Matthew A. Koenig, M.D.

Semin Neurol 2008;28:611-630. Copyright (C) 2008 by Thieme Medical Publishers, Inc., 333 Seventh Avenue, New York, NY 10001, USA. Tel: +1(212) 584-4662.

DOI 10.1055/s-0028-1105970. ISSN 0271-8235. 
and care of the neurological patient. Patients are more likely to be awake and responsive than in previous eras of critical care, and also less apt to suffer adverse effects of neuroactive agents, many of which can induce cognitive and motor dysfunction beyond their intended actions. Maximizing patient comfort with preserved wakefulness has also forced a pharmacological reassessment of the medications selected, dosing intervals, routes and modes of administration, and the monitoring of their effects. Guidelines now place emphasis on minimizing the depth and duration of sedation, advocating intermittent periods of arousal, and a titration scheme to afford the least medication necessary to achieve a comfortable and controlled behavioral state.

With respect to bedside evaluation and titration of sedation, the neurologically injured patient may indeed be the most difficult ICU population to manage. Cognitive dysfunction leads to increased fear, restlessness, and agitation from the inability to understand one's predicament. Yet, even modest sedation may mask subtle neurological deterioration. Hence, the need for an interdisciplinary approach to patient care as it relates to observation, and titrating medications as necessary without impairing neurological evaluation. Such tenets have now found a broader critical care audience. Sedative regimens in neuroscience-specific ICUs have been designed to enable repeated acquisition of a high-quality neurological examination as the principle means of assessing patient status. ${ }^{5}$

\section{THE NEED FOR SEDATION OR ANALGESIA IN THE INTENSIVE CARE UNIT}

There are several clinical triggers for ordering analgesia or "sedation," the latter a particularly inclusive term embracing the treatment of many distressing clinical circumstances. This pharmacological therapy is commonly used to indicate provision of analgesia, anxiolysis, antipsychosis, or a combination thereof. Correct diagnosis of a single or overlapping disturbance thus becomes the starting point, as there are medications with broad therapeutic effects as well as those directed toward a specific pathology. To minimize toxicity and side effects, it is best to select agents appropriate for the indication.

\section{Management of Pain}

The prerequisite for analgesic therapy is discomfort. Unfortunately, the ICU is replete with reasons for patients to complain of pain (Table 1). Most are due to primary physiological discomfort associated with focal disease or injury (e.g., broken bones, surgical incisional pain), and other forms of superficial or visceral discomfort that may have poorly localizable foci. Pain may also occur as a primary consequence of neurophysiological dysfunction as in the case of neuropathic pain, headache, intracranial pressure elevation, etc. Unfortunately, critical care therapies such as mechanical ventilation, therapeutic suctioning, patient turning and positioning often cause discomfort. Not all pain should be suppressed in its entirety, particularly discomfort that provides a clinical guide to the evolution of a pathological process, such as an acute abdomen or compartment syndrome. Nevertheless, studies have demonstrated that patients cared for in an ICU are apt to be in considerable discomfort during some portions of their stay, and overall management of pain during critical care has remained suboptimal. In a recent large series of mechanically ventilated patients, procedural discomfort was specifically managed in less than $25 \%$ of the population, and the use of guidelines for analgesia and sedation promoted less, not more, therapy for pain management. ${ }^{1}$ Specific to procedures, a nursing report documented that patients commonly expressed great differences between pre- and postprocedural levels of discomfort with interventions like drain removal, deep breathing and coughing exercises, suctioning, and line removal. ${ }^{6}$ In that series, less than $50 \%$ of patients received preprocedural analgesia. The authors also noted that routine monitoring of hemodynamic parameters such as heart rate and blood pressure often failed to serve as indicators of patient discomfort.

To quantify patient discomfort, there is a considerable number of pain measures employed in the ICU

Table 1 Examples of Patient Pain Syndromes in the Intensive Care Unit

\begin{tabular}{llll}
\hline Localized Pain & Diffuse Visceral & Neurological & Complex \\
\hline Surgical wound & Acute abdomen & Intracranial hemorrhage & Mechanical ventilation \\
Bone fracture & Myocardial ischemia & Headache-migraine & Diffuse joint pain-arthralgia \\
Ulceration & Pneumonia & Elevated intracranial pressure & Sickle cell \\
Pleurodynia & Myocarditis & Compressive neuropathy & Metabolic disorders \\
Invasive procedure & Pulmonary embolus & Subarachnoid hemorrhage & Febrile-sepsis \\
Local burn injury & Vascular ischemia & Cranial neuritis & \\
Compartment syndromes & Gastritis & Diabetic neuropathy & \\
Ureteral stone & Pancreatitis & Reflex dystrophy & Meningismus \\
Appendicitis & Bowel obstruction & P &
\end{tabular}


setting. Some are used primarily in awake, responsive patients, such as the Numerical Rating Scale (1 to 10) and the Visual Analog Scale (VAS, 1 to 100). ${ }^{7}$ Other quantitative measures have been adopted to assess discomfort in patients unable to self-rate their level of pain as in the case of a sedated, mechanically ventilated patient. Such examples include the Behavioral Pain Rating Scale (BPRS), ${ }^{8}$ Behavioral Pain Scale (BPS), ${ }^{9}$ Critical-Care Pain Observational Tool (CPOT), ${ }^{10}$ Nonverbal Pain Scale (NVPS), ${ }^{11}$ and the Pain Assessment and Intervention Notation (PAIN) algorithm. ${ }^{12}$ All of the latter scoring devices include measures of a variety of behavioral dimensions to provide a comprehensive assessment in the nonverbal patient. Both the BPRS and the BPS have undergone complete content, criterion, and construct validity testing, and the BPS has further documented interrater reliability testing. ${ }^{7}$ Many studies assessing quantification of pain in ICU patients have demonstrated that self-reporting of discomfort indeed has the greatest correlation with multidomain behavioral ratings compared with single item scoring. ${ }^{13}$

Unfortunately, ICU pain management regimens risk diminishing overall level of arousal when administered to eliminate all of the patient's perception of pain or stigmata of discomfort. In lieu of such a hazard, especially in the neurologically compromised patient, analgesia should be titrated to effect with preservation of responsiveness, typically to reduce the pain to less than a 3 on a 0 to 10 ordinal scale. Medications utilized include nonsteroidal antiinflammatory drugs (NSAIDS; aspirin, acetaminophen, ibuprofen, ketorolac), narcotics (both pure and mixed mu-opioid receptor agonists), $\alpha_{2}$ agonists (clonidine and dexmedetomidine), steroids, ketamine, and local anesthetics.

\section{Anxiolysis}

Aside from the treatment of pain, anxiolysis represents the therapy most sought after when delivering "sedation." Anxiolysis is the provision of pharmacotherapy to lessen feelings of apprehension/ anxiety, diminish general nervous tension or "stress," and to treat the most severe form of excited disequilibrium - agitation. Psychologically demanding circumstances in critical care are numerous, with common general ICU stressors being the psychological responses to a life-threatening illness, unfamiliar surroundings, near constant noise and activity, disturbed sleep-wake cycles, and an overall sense of lack of control. Specific ICU treatments and conditions that add to this mix include endotracheal intubation and mechanical ventilation, need for restraints, traumatic head injury, sepsis, febrile state, medication effects, and other etiologies of encephalopathy.

Because both pain and anxiety are commonly combined, it is important to discern if pain is paramount, leading to agitation, or if anxiety/agitation are separate signs or symptoms. Several agents are very effective in anxiolysis, such as the benzodiazepines and the sedative/ hypnotic agents like the barbiturates and propofol. Some provide both analgesia and anxiolysis: $\alpha_{2}$-agonists, ketamine, and some narcotics in low doses.

\section{Delirium}

Delirium is a dysfunctional cognitive state that has gained great interest as a predictor of poor outcome in hospitalized patients, particularly in the ICU. ${ }^{14,15} \mathrm{It}$ often goes unrecognized because the diagnosis is not specifically entertained or the clinical features are confounded by coincident neurological disturbances. Specific scoring batteries have been designed for diagnostic purposes ${ }^{14}$ and their introduction has led to data supporting that delirium is an independent predictor of longer hospital stay, greater mortality, and ICU costs. ${ }^{15}$ It remains unclear, however, whether all forms of delirium are equally hazardous. Especially in the ICU setting, a number of conditions incite delirium in a transient or persistent manner, each of which has different effects on the patient's physiological state. Several examples include metabolic dysfunction, electrolyte abnormalities, relative hypoxia, acid-base disturbances, drug-induced cognitive dysfunction, and loss of adequate sleep and sleep-wake cycling. It still remains to be seen whether effective treatment of delirium improves these indices.

Once a decision is made to treat an individual with sedative medications, the choice of pharmacotherapy is expansive. There exist many classes of drugs, including the narcotics, benzodiazepines, barbiturates, propofol, neuroleptics, $\alpha_{2}$-adrenergic agents, ketamine, and several others. Each has advantages and disadvantages in the ICU patient, as well as varied pharmacokinetics, routes of administration, titratability, adverse reactions, and hemodynamic profiles. It is generally recommended that shorter-acting agents be used in the critical care setting when serial neurological examinations are important. ${ }^{5}$ Where relevant, the reversibility, drug-drug interactions, and cost-effectiveness also need to be discussed. A summary of the main characteristics of preferred sedatives and analgesics in ICU patients is presented in Tables 2 and 3 .

It is, of course, necessary to eliminate all alternative explanations for agitation, confusion, or sympathetic hyperactivity prior to actively suppressing potential symptoms and signs of a serious underlying condition. Hypoxemia or hypercarbia related to decreased respiratory drive or poor airway protection must be detected and treated appropriately. Metabolic disturbances, including acidosis, hyponatremia, hypoglycemia, hypercalcemia, hyperamylasemia, hyperammonemia, or hepatic or renal insufficiency may contribute to behavioral changes in critically ill patients. Cardiac ischemia, infection, and hypotension, which often may 

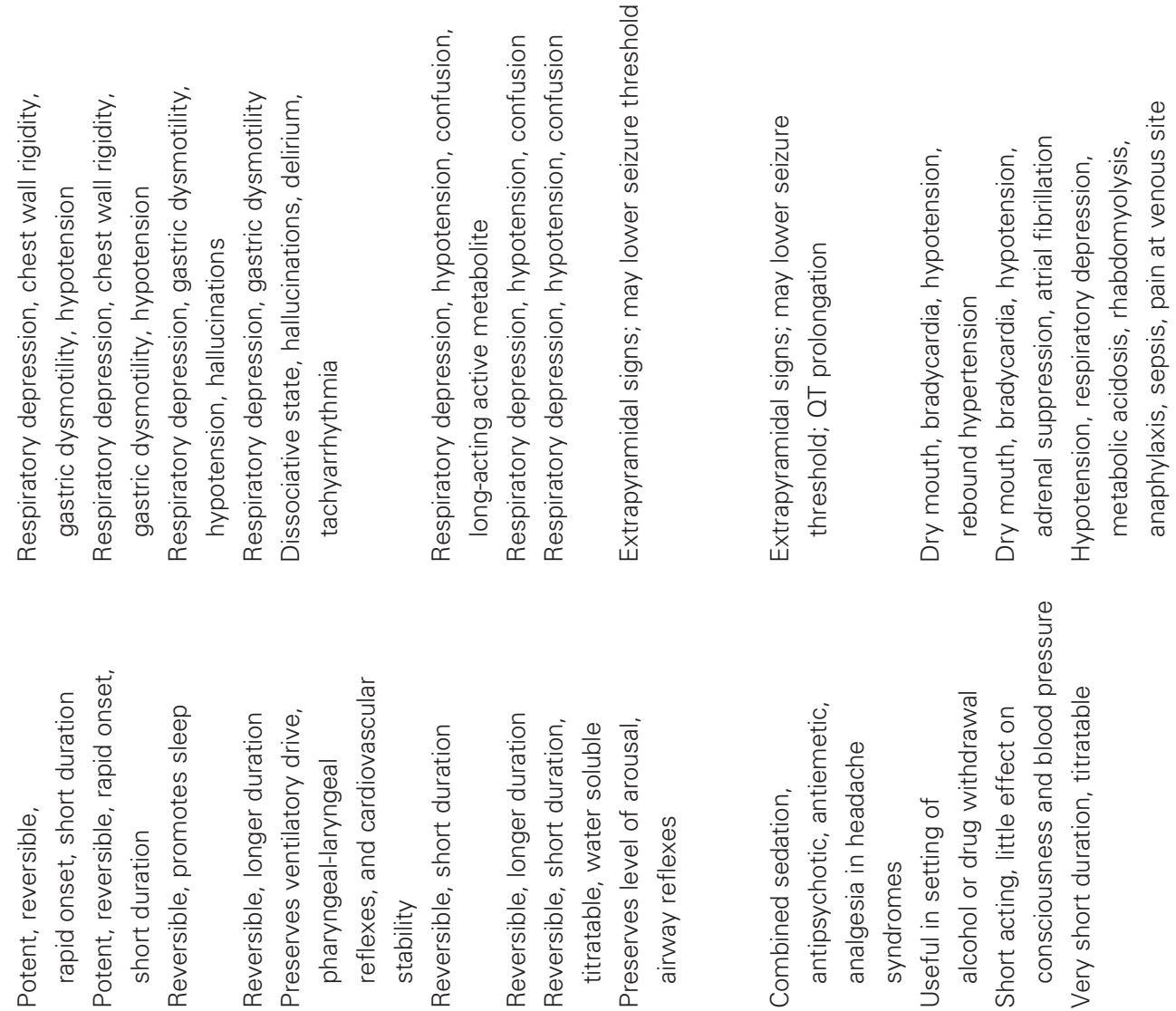

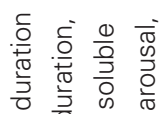

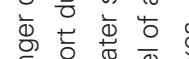

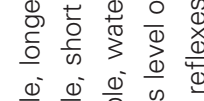

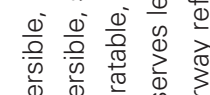

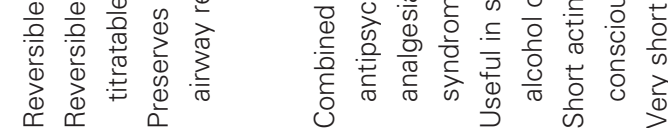

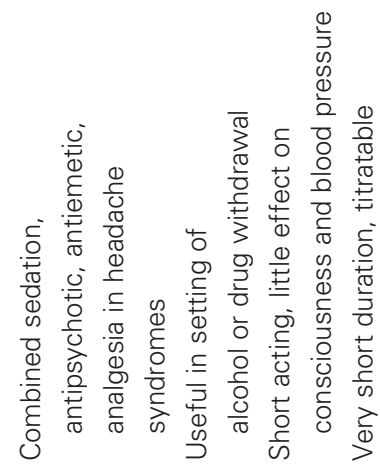

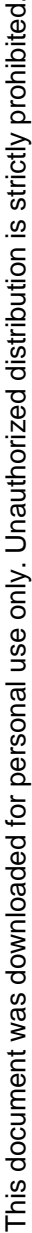

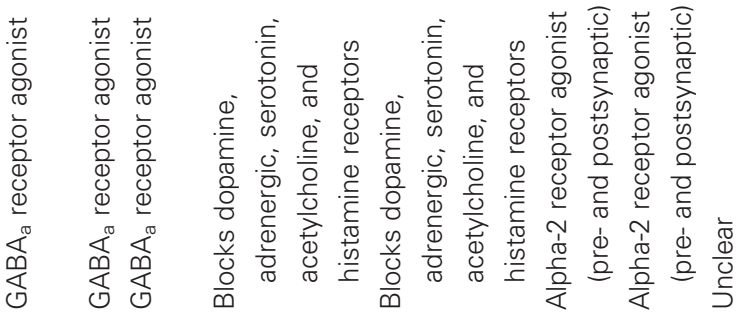

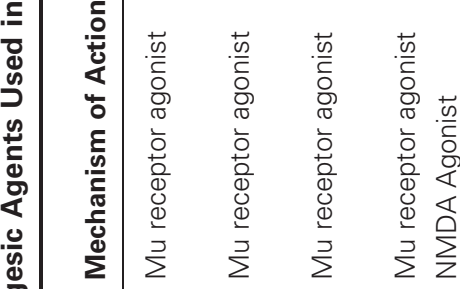

$\begin{array}{llll}+ & + & + & + \\ + & + & + & +\end{array}$

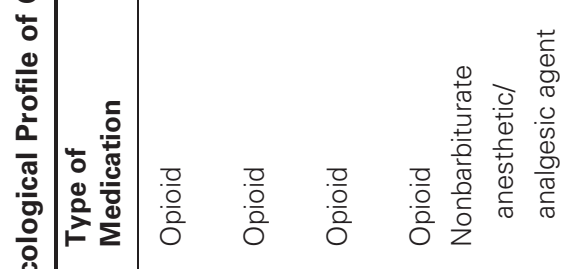

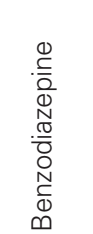

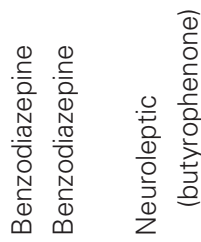

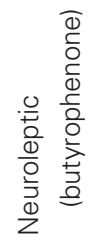

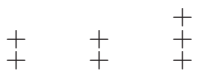

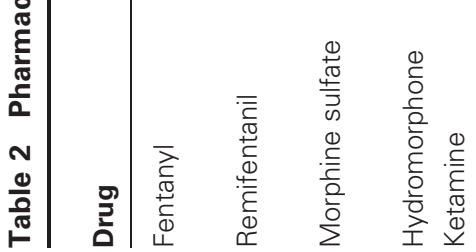

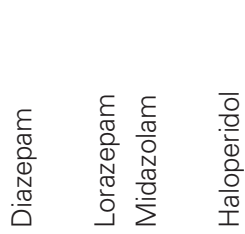
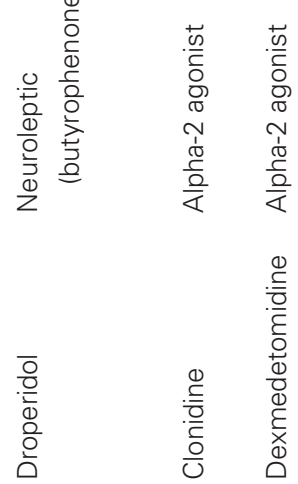

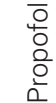




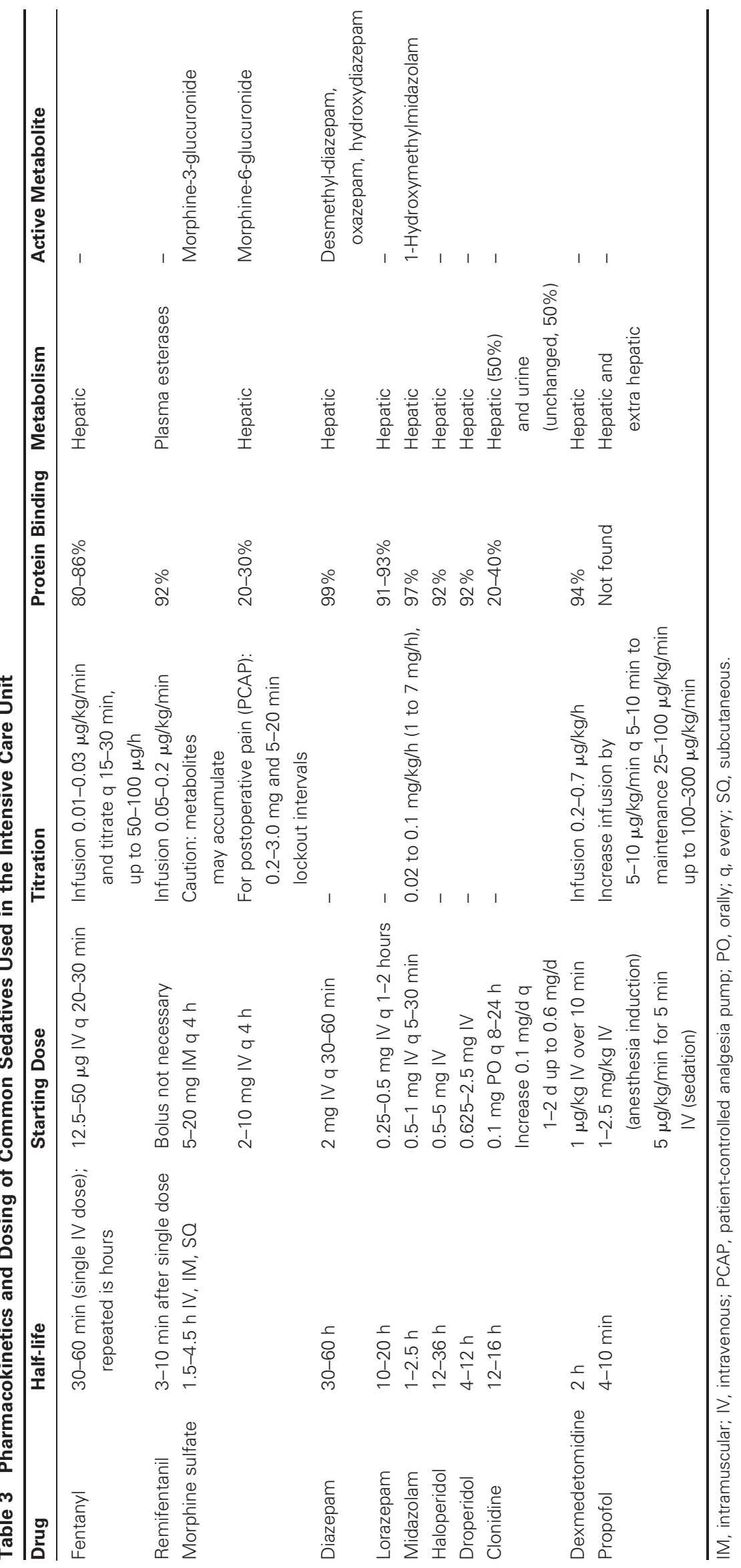


be associated with cerebral hypoperfusion, contribute to mental status changes, and must be ruled out as a cause of delirium in the critically ill. Psychoactive medications such as antidepressants, anticonvulsants, and other commonly used medications may promote cognitive dysfunction and agitation.

\section{MONITORING OF SEDATION}

To monitor the administration of sedatives, particularly in the ICU where frequent dosing and titrations are necessary, numerous sedation scoring systems have been crafted. The first scale popularized was the Ramsay Scale introduced in 1974, which is representative of the sedation goals that were popular at that time. Focused primarily on the postcardiac surgery patient, the Ramsay Scale places great emphasis on deep levels of sedation, with the clinical target arousal level being the semi- or fully unconscious state. ${ }^{16}$ Three of the six stages of sedation are within the asleep or unconscious state, one describes a sedated but awake phase, and one corresponds to an anxious/agitated condition. Subsequently, in an effort to focus on less obtunded states of sedation and to delineate exaggerated levels of arousal-restlessness and agitation-evaluation tools were devised that placed greater descriptive weight on specific motor behaviors and hemodynamic parameters. Recent scoring tools include the Riker Sedation-Agitation Scale (SAS, 1999), ${ }^{17,18}$ Motor Activity Assessment Scale (MAAS, 1999), ${ }^{19}$ the Richmond Agitation-Sedation Scale (RASS, 2002), ${ }^{20}$ and recently the Adaptation to the Intensive Care Environment Scale (ATICE; measuring sedation and tolerance), ${ }^{21}$ and AVRIPAS Scale (four components: agitation, alertness, heart rate, and respiration). ${ }^{22}$ Of those listed, only the RASS has been validated for its ability to detect changes in sedation status over consecutive days. ${ }^{23}$ Some intensivists have argued that representation of several domains of level of arousal-including cognitive state and degrees of anxiety or agitation-into a single numerical value diminishes the potential utility of an assessment tool. Two-domain instruments have therefore been developed and validated, and include the Vancouver Interaction and Calmness Scale (VICS) and the Minnesota Sedation Assessment Tool (MSAT) scale (see Appendix for specific scales). ${ }^{24,25}$ All such scales have utility in monitoring sedation, and a tool should be routinely used in all sedated ICU patients to provide an objective target for the depth of sedation, to minimize the amount of drug required to obtain the sedation goal, and to facilitate communication among providers. Selection depends primarily on the particular needs of an ICU, in particular their efficiency in the transfer of well-categorized patient status from one caregiver to another, and in charting a patient's arousal state over time in the medical record.

\section{Physiological and Brain Functional Monitors}

There have been attempts to effectively titrate sedative agents in an ICU using both a patient's hemodynamic response to pharmacological intervention and changes in cerebral electrical function. Although logical and often presumed, neither heart rate nor blood pressure changes have been supported in studies as useful parameters for guidance. In fact, published guidelines for sedation specifically discourage their use as markers of sedation. ${ }^{26}$ The neurological monitors have their origin in the raw electroencephalogram (EEG), and typically have been variants of signal-processed EEG and more recently the bispectral index (BIS) monitor. These evolved devices take EEG data from the frontal cortex via a dual electrode patch and generalize the electrical phenomena to a global state. The BIS is by far the most tested proprietary algorithm that compares the patient's frontal EEG to a processed dataset from over 5,000 volunteer EEG samples to scale the output of the measured EEG to between 0 and 100 . The "fully awake state" is scored 100 , whereas 0 is an isoelectric EEG reading. The score of 60 is the fundamental threshold established by the proprietary analysis that places the patient at high probability of unconsciousness with a reading below 60. For general anesthetic purposes, a range of 40 to 60 is commonly used, whereas sedation targets are typified by ranges of 60 to 75 .

Although some ICUs enjoy the benefits of a simple numerical scale to assist physician/nursing titration of sedation, particularly when continuous infusions of medication are used, the BIS monitor suffers from several shortcomings. From a pharmacological perspective, the BIS is best used when administrating a short acting barbiturate anesthetic (thiopental) or barbituratelike drug (propofol) on which the processed EEG algorithm is based. These agents induce a very stereotypic alteration in the EEG as a patient transitions from the completely awake to the sedated and finally unconscious/comatose state. Agents such as the benzodiazepines, narcotics or other classes of sedatives differentially influence the EEG, and the BIS is not programmed to interpret such changes as well. ${ }^{27-29}$ For example, benzodiazepines and propofol cause a rise in EEG frequency following modest to moderate doses rather than slowing. Narcotics, on the other hand, can have a profound effect on a patient's state of anxiety without untoward disturbance on the underlying cortical EEG. Combination pharmacotherapy also makes it difficult to readily translate a BIS "score" to a clinical state of arousal as different agents have such varying actions on the EEG as they contribute to the sedation scheme. Another major limitation of using the BIS as an ICU sedation monitor stems from the inability of the device to fully eliminate the electromyographic (EMG) signal artifact that originates from the frontalis muscle underneath the electrode patch, contaminating the EEG signal input and 
rendering the numerical output unreliable under conditions of a pharmacologically nonparalyzed state.

\section{CLASSES OF SEDATIVE AGENTS}

\section{Narcotics (Opioids)}

A large number of natural opioids (e.g., morphine sulfate, codeine), semisynthetic opioids (e.g., fentanyl, hydromorphone, oxycodone), and completely synthetic (e.g., meperidine) opioid-like compounds are available. These compounds act primarily as analgesics, but also serve as sedative-hypnotics at low dosages. Their major disadvantage is their coincident action of suppressing ventilatory drive and gastrointestinal motility. Advantages include easy titratability, provision of patient comfort, and reversibility. Three opioids in particular are common sedative-analgesics used in the critical care setting-morphine, fentanyl, and remifentanil.

\section{MECHANISM OF ACTION}

All opioids act by binding to mu-opioid receptors in the central and peripheral nervous systems as agonists, partial agonists, or agonist-antagonists. ${ }^{30}$ These receptor interactions are the basis for the pharmacological effects of opioids (analgesia, decreased level of consciousness, respiratory depression, miosis, gastrointestinal hypomotility, antitussive effects, euphoria or dysphoria, and vasodilatation), and vary by the specific opioid receptor subtypes bound by each drug.

Of particular interest to clinicians using narcotics for sedation and analgesia is the recent evidence that the mu-opioid receptor (MOR-1) is constructed via a translation of a combination of exon fragments of the MOR-1 gene. Certain exon fragments define the receptor complex at the cell surface for all variants of the MOR-1 construct, thus supporting the observation that all $\mathrm{mu}$ receptor opioid agonists have similar high affinity for the receptor. However, the interior cell receptor component is composed of a variety of potential constructs owing to the possible mix of splice variants from at least five potential exon fragments. Thus, although all opioids bind to the mu receptor (MOR-1), the physiological response may vary from individual to individual, owing to the receptor differences located inside the cell. This phenomenon may help explain the subtle distinctions between drugs and support the concept that opioid administration - both type and dose-needs to be tailored to each patient. ${ }^{31}$

\section{PHARMACOKINETICS AND DYNAMICS}

Opioids are readily absorbed through mucosal surfaces, from the gastrointestinal tract, or through subcutaneous (SQ), intramuscular (IM), intrathecal (IT), epidural, and intravenous (IV) routes of administration. ${ }^{30}$ Fentanyl is also easily absorbed via transdermal application.
Morphine and other opioids are rapidly distributed to the brain, with the more lipophilic compounds (e.g., fentanyl, remifentanil) having the shortest time of onset. Peak effect following IV administration of morphine is $\sim 15$ minutes; for fentanyl, it is 5 minutes; for remifentanil, it is 1 to 2 minutes.

After enteral administration, the bioavailability of morphine sulfate is only $\sim 20$ to $40 \%$ due to first pass hepatic metabolism. IM and IV morphine sulfate is rapidly and readily available. Morphine is 20 to $36 \%$ protein bound in plasma, and has a volume of distribution $(\mathrm{Vd})$ of 1 to $6 \mathrm{~L} / \mathrm{kg}$, depending on route of administration. However, the majority of systemically administered morphine does not cross the blood-brain barrier (BBB).

Morphine is eliminated in the liver by $\mathrm{N}$-demethylation, $\mathrm{N}$-dealkylation, $\mathrm{O}$-dealkylation, conjugation, and hydrolysis. The majority of clearance is by glucuronidation to the active metabolites, morphine-3-glucuronide ( $\sim 50 \%)$ and morphine-6-glucuronide (5 to $15 \%)$, which are renally excreted; the latter is a more potent analgesic than the parent compound, and may accumulate in patients with renal insufficiency. The half-life of morphine varies greatly by route of administration, ranging from 1.5 to 4.5 hours for IV, IM, and SQ injection, to 15 hours or more for sustained-release oral preparations.

Time to onset following buccal administration of fentanyl is 5 to 15 minutes, with a peak response at 20 to 30 minutes. For IM injection of fentanyl, the onset is at 7 to 8 minutes and effects last 1 to 2 hours. Transdermal fentanyl has a much slower onset of action, 12 to 24 hours, although the rate of absorption increases with higher skin temperature (e.g., febrile patients). Steady state is reached at 36 to 48 hours, and duration of action is up to 72 hours after removal of transdermal fentanyl. Following IV administration, the onset of action of fentanyl is immediate, although peak effects take several minutes to manifest. Duration of action after a single IV dose of fentanyl is 30 to 60 minutes, which increases after repeated or prolonged dosing due to accumulation in fat and skeletal muscle.

Fentanyl is extensively plasma protein bound (80 to $86 \%$ ), with a $\mathrm{Vd}$ of 3 to $6 \mathrm{~L} / \mathrm{kg}$ in adults. Fentanyl is metabolized via $N$-dealkylation by the hepatic cytochrome P450 system, producing norfentanyl and other inactive metabolites, which are renally excreted. Halflife is 200 minutes following IV injection, and up to 17 hours for transdermal administration. As up to $10 \%$ of fentanyl is excreted unchanged in the urine, its duration of action may be prolonged following high cumulative doses in patients with renal insufficiency. Fentanyl does not appear to be removed from the plasma compartment by hemodialysis.

Remifentanil is typically given by IV infusion, with a time to peak onset of action of 1 to 3 minutes. 
Duration of action is only 3 to 10 minutes after a single dose, increased slightly after prolonged infusions. Remifentanil is $92 \%$ plasma protein bound, with a $\mathrm{Vd}$ of 25 to $60 \mathrm{~L} / \mathrm{kg}$ and a distribution half-life of 1 minute. Remifentanil is rapidly metabolized by plasma esterases to an inactive carboxylic acid, which is $90 \%$ renally excreted. Metabolism is independent of the cumulative remifentanil dose, and unaffected by hepatic or renal function.

Due to its rapid onset and short duration of action, which is independent of hepatic and renal clearance, remifentanil is the most easily titratable of the opioids. Preliminary use of a continuous remifentanil infusion for sedation of intubated patients in an ICU setting has shown promising results, with blunting of hemodynamic instability and intracranial hypertension associated with agitation, coughing, and tracheal suctioning. It is expensive relative to fentanyl or morphine, but when the need to have a true on-off drug arises, remifentanil possesses ideal pharmacokinetic properties. The downside of the ultrashort half-life of remifentanil is evident upon abrupt discontinuation of the infusion (this is analogous to rapid reversal with naloxone), which can precipitate acute exacerbations of pain, or possibly withdrawal in patients receiving long-standing opioid therapy. For this reason, it is imperative that a plan for transition to a longer-acting opioid and strategy for pain management be implemented prior to discontinuation.

Fentanyl is often more readily accessible than remifentanil in many medical centers, and many physicians are more familiar with this intravenous opioid. Fentanyl may be given by either bolus dosing or continuous IV infusion. Due to its lipophilic nature and longer clearance time, however, fentanyl may be less easily titrated than remifentanil and require greater periods of drug interruption to permit frequent neurological assessment. However, doses of 1 to $2 \mu \mathrm{g} / \mathrm{kg} / \mathrm{h}$ are typically well tolerated, and continuous uninterrupted infusion for several days can provide analgesia/sedation with minimal neurological or respiratory compromise. Morphine is the most difficult of these opioids to titrate, again due to its longer duration of action, dependence on hepatic and renal clearance, and prolonged clearance of active metabolites. For these reasons, infusions of morphine are not recommended for ICU patients requiring short-term sedation, although intermittent administration may facilitate patient comfort and hemodynamic stability.

Comparing remifentanil and fentanyl, a recent randomized, double-blind trial of ICU sedation found that analgesia-based sedation with each of the two agents provided effective sedation and rapid extubation without the need for propofol in most patients. Fentanyl was similar to remifentanil with respect to the achievement of an appropriate level of sedation and time to extubation when discontinued after 12 to 72 hours of continuous sedation ( 1 to $2 \mu \mathrm{g} / \mathrm{kg} / \mathrm{h}$ ). ${ }^{32}$ Sedation with remifentanil incurred the risk of higher degrees and longer duration of pain upon discontinuation than fentanyl. These results emphasize the need for proactive pain management when discontinuing remifentanil and transitioning to longer acting analgesics during the weaning period.

One of the advantages of sedation with opioids is their rapid reversibility with the antagonist naloxone. Although the recommended dosage for reversal of narcotic overdose is generally $0.4 \mathrm{mg}$ or above, ${ }^{30}$ in ICU patients the starting dosage should be lower (e.g., 0.04 to $0.08 \mathrm{mg}$ by IV push) to avoid "overshoot" phenomena such as hypertension, tachycardia, and emergence agitation, all of which may precipitate or worsen myocardial ischemia, ventilatory mismatch, or intracranial hypertension. Dosage may be titrated to the desired level of arousal and reversal of respiratory depression, with effects seen within 1 to 2 minutes of each subsequent administration.

\section{RATIONALE FOR ICU USE AND ADVERSE REACTIONS}

The narcotics are a highly useful drug class in the ICU. Analgesia is commonly required, and the opioids are typically well-tolerated with minimal adverse physiological effects. Although modest bradycardia can occur with high-dose narcotic administration, typically these agents have little or no effect on chronotropy or systemic pressure. Caution has been issued regarding administration of morphine to patients with traumatic brain injury (TBI) due to increases in intracranial pressure (ICP), although the mechanism is unclear. In general, opioids per se have no effects on ICP or cerebral blood flow (CBF), ${ }^{30}$ but hypercarbia related to respiratory depression by opiates may lead to cerebral vasodilatation and its sequelae. Very high doses of both morphine and fentanyl ${ }^{33}$ have been shown to induce seizure-like activity in patients undergoing general anesthesia. As none of these cases had documented electrographic seizure activity, some others have suggested that the reported "seizures" were actually manifestations of narcotic-induced rigidity or myoclonus. ${ }^{34}$ Indeed, nonepileptic myoclonus has been reported in numerous cases when very high doses of IV or IT morphine were given. ${ }^{35}$ Meperidine has a renally eliminated active metabolite, normeperidine, which has been associated with an excitatory syndrome that includes seizures. Patients with underlying renal dysfunction are particularly susceptible to this.

Common adverse responses of narcotics include pruritus, excessive somnolence, respiratory depression, chest wall and other muscular rigidity (primarily fentanyl and other high potency opioids), dysphoria or hallucinations (primarily morphine), nausea and vomiting, gastrointestinal dysmotility, hypotension, histamine release causing urticaria and flushing (primarily meperidine and morphine), anaphylaxis (rare), and 
immune suppression after repeated dosing. ${ }^{30,36}$ Although morphine may induce hypotension even at low therapeutic doses (partly due to promotion of histamine release), ${ }^{36}$ fentanyl and remifentanil tend to have little effect on blood pressure at sedative doses. Fentanyl also tends to reduce heart rate, which is favorable in the setting of cardiovascular disease. Because of their potential to suppress respiratory drive, it is recommended that all patients receiving narcotic sedation have frequent (preferably continuous) monitoring of pulse oximetry and respiratory rate. Additional frequent hemodynamic assessments, including blood pressure and heart rate, are prudent due to the potential for hypotension, bradycardia, and tachycardia with selective narcotic agonists.

\section{DRUG-DRUG INTERACTIONS}

Combined use of morphine and neuroleptics may produce greater than expected decreases in blood pressure. Additionally, the depressant effects of narcotics on respiration and level of consciousness may be potentiated by concurrent administration of phenothiazine neuroleptics, tricyclic antidepressants, and monoamine oxidase inhibitors. $^{30}$

\section{DOSAGE RECOMMENDATIONS}

Dosage recommendations are for narcotic-naïve patients. As a general guideline, fentanyl and remifentanil are $\sim 100$ times more potent than morphine.

Fentanyl Although fentanyl may also be given by buccal, transdermal, IM, IT, and epidural routes, IV administration is recommended for ICU patients. For mild sedation and analgesia, recommended starting dosage is 25 to $50 \mu \mathrm{g}$ IV every 5 to 10 minutes until comfort is achieved, recognizing that time-to-peak is $\sim 3$ minutes following each dose. Thus, the next dose occurs as the previous effect begins to wane. A cumulative effect gradually occurs. Alternatively, for more durable effect, a continuous infusion of 0.5 to $2.5 \mu \mathrm{g} / \mathrm{kg} / \mathrm{h}$ may be used, titrating to effect every 15 to 30 minutes. Continuous infusions above $2 \mu \mathrm{g} / \mathrm{kg} / \mathrm{h}$ are not recommended in narcotic-naïve patients unless they are endotracheally intubated or otherwise have a protected airway, and mechanical ventilation is possible. For deeper sedation, as an adjunct to general anesthesia, or in narcotictolerant patients, continuous infusions greater than those above may be advocated.

Remifentanil Being extremely short acting, remifentanil can be effectively and quickly titrated by continuous infusion. Dosing range for sedation begins at $\sim 0.02$ to $0.05 \mu \mathrm{g} / \mathrm{kg} / \mathrm{minute}$, and upwards as needed to a typical maximum of $0.1 \mu \mathrm{g} / \mathrm{kg} /$ minute. Larger doses rapidly lead to apnea and general anesthesia. No adjustment is needed for renal or hepatic insufficiency, although de- creasing the dose by $50 \%$ is recommended for patients older than 65 years of age.

Morphine Sulfate The time-to-peak of this longer acting narcotic is 20 to 30 minutes with duration of $\sim 4$ hours. Thus, intermittent bolus delivery constitutes a sensible dosing regimen. For analgesic dosing, titration doses of 5 to $20 \mathrm{mg}$ IM every 4 hours or 2 to $10 \mathrm{mg} \mathrm{IV}$ over 4 to 5 minutes every 2 to 4 hours is recommended. Preference should be given to IV dosing in an ICU setting to minimize patient discomfort. For oral dosing when appropriate, 15 to $30 \mathrm{mg}$ of the immediate release (IR) formula every 4 hours is reasonable.

These dosages are for narcotic naïve individuals, and may be increased substantially (with appropriate monitoring) in patients tolerant to opioids. It is quite common to admit patients to an ICU with preconditions requiring large doses of oral opioids at baseline. These patients are best served by initial bedside titration of IV fentanyl until immediate discomfort is relieved. This minimizes the time to comfort. It is not unusual in some circumstances to titrate upwards of $1000 \mu \mathrm{g}$ of fentanyl over a 30-minute time span in a highly narcotic-tolerant patient. Thereafter, logical dose substitution for a longer acting agent such as morphine is warranted. Due to hepatic metabolism and renal clearance, dosages should be reduced in patients with hepatic or renal insufficiency or those at the extremes of age.

\section{Benzodiazepines}

Benzodiazepines rank as the most common agent used for ICU sedation. Three principal agents are found within this category that are commonly used in the ICU; diazepam, lorazepam, and midazolam. These medications are sedatives by virtue of a predominantly anxiolytic action. Some analgesic effect has been suggested for diazepam via GABAergic receptor function. ${ }^{37}$

\section{MECHANISM OF ACTION}

The majority, if not all, of the effects of benzodiazepines are through potentiation of the central nervous system actions of the inhibitory neurotransmitter, gamma aminobutyric acid (GABA). Benzodiazepines experimentally increase the frequency of opening of the GABA chloride channel in response to binding of GABA. ${ }^{37}$ Subsequent effects include anxiolysis, sedation, muscle relaxation, anterograde amnesia, respiratory depression (especially in children, patients with chronic pulmonary disease, hepatic insufficiency, or when combined with other sedatives), anticonvulsant activity (not all benzodiazepines), and analgesia (only IV diazepam). Very high doses of several benzodiazepines will also lead to coronary vasodilatation and neuromuscular blockade through interaction with peripheral sites. ${ }^{37}$ 


\section{PHARMACOKINETICS AND DYNAMICS}

Time to onset and offset of single IV doses of a benzodiazepine is largely determined by the agent's relative lipophilicity. Upon a single IV injection, benzodiazepines are rapidly distributed to the brain, followed by redistribution to muscle and fat. Of the three, diazepam is the most rapid in onset, and likewise the most rapidly redistributed due to its higher lipophilicity, followed by midazolam and lorazepam. With multiple doses or continuous infusions, the time to offset is more dependent on the agent's half-life, and presence or absence of active metabolites. Thus, diazepam has a very short onset time and initial duration of effect following a single bolus (due to redistribution), but has the longest half-life of $>50$ hours. In addition, a primary metabolite, dimethyl-diazepam, retains considerable potency as a sedative, and with its elimination half-life of $>90$ hours, may prolong recovery from the effects of repeated dosing or lengthy infusion of the agent. ${ }^{38}$ Midazolam is most easily titratable as an IV drug, owing to its shorter duration of action and shortest half-life ( 1 to 4 hours); it is most appropriate for use as a continuous infusion. Midazolam does possess an active metabolite ( $\alpha$-hydroxy-midazolam), which is renally eliminated. Accumulation of this metabolite in the renally impaired may contribute to prolonged sedation. Lorazepam is the most water soluble with the smallest redistribution effect, which enhances its duration of action following a single bolus. Thus, duration of 4 to 6 hours may be expected following a single dose, as compared with 5 to 20 minutes following either midazolam or diazepam. Lorazepam does not possess any active metabolites. All benzodiazepines are highly bound to plasma proteins, and all are hepatically metabolized. ${ }^{38}$

Benzodiazepines are reversible with the selective antagonist, flumazenil. ${ }^{3,39}$ Caution must be exerted with flumazenil, however, as this agent may precipitate rapid rises in ICP, systemic hypertension, and lowering of seizure threshold, ${ }^{39}$ particularly in TBI and neurosurgical patients. Additionally, because of its short duration of action, patients may become resedated from longeracting benzodiazepines after flumazenil has been metabolized.

\section{RATIONALE FOR ICU USE AND ADVERSE REACTIONS}

As anxiolytics and amnestics, benzodiazepines provide often-needed relief from the stressful ICU environment. Small, titrated doses can usually be given to effect without overt compromise of cognitive function. Anterograde amnesia is a profoundly useful attribute when performing discomforting procedures, although analgesia should also be offered. Similar to the opioids, benzodiazepines provide their positive effects without undo alteration in either blood pressure or heart rate, and respiratory drive is well preserved unless high doses are entertained. Low (oral hypnotic) doses of benzodiaze- pines have little effect on blood pressure, but higher IV (sedative or anesthetic) doses may cause hypotension and increased heart rate. Alone, benzodiazepines have little or no effect on ICP. ${ }^{40}$ However, decreases in mean arterial pressure associated with midazolam administration may impair cerebral perfusion. As with opioids, high doses of benzodiazepines may induce respiratory dysfunction and apnea, and the hypercarbia associated with these respiratory-depressant effects may stimulate an increase in ICP. ${ }^{41}$

With that stated, the most common unintended action from use of the benzodiazepines is oversedation, but it is dose-dependent and usually avoidable. Another unintended consequence of benzodiazepine administration is inducing frank delirium. Although a tranquil state coupled with anterograde amnesia is the principal reason for their use, these agents also precipitate altered cognition that defines, in part, the delirious state. Delirium is diagnosed if features of acute onset of mental status change or fluctuating level of consciousness occur along with inattention and disorganized thinking or altered level of consciousness are present. There have been recently developed measures for the screening of delirium such as the Confusion Assessment Method for the Intensive Care Unit (CAM-ICU) or Intensive Care Delirium Screening Checklist. ${ }^{42,43}$ Clearly, benzodiazepines may contribute to delirium, and this likely adverse event must be considered when administration of this drug class is initiated. ${ }^{44}$

With nearly all sedative agents, additive or synergistic effects may occur with benzodiazepines and any other medication that may alter level of consciousness, suppress respiratory drive, or decrease systemic blood pressure. In particular, apnea can commonly be precipitated when benzodiazepines are used in conjunction with opioids, and caution must be used when this combination therapy is pursued. As with opioid narcotics, the potential for respiratory depression and hypotension with highdose benzodiazepines necessitates careful monitoring of pulse oximetry and blood pressure. This is especially prudent in patients maintained on continuous infusions, and those who are not mechanically ventilated.

An adjunctive benefit to the neurological population is the anticonvulsant property of the benzodiazepines, and data support them as primary therapy for treatment of acute seizures, including convulsive status epilepticus. ${ }^{45}$ In this regard, lorazepam is the recommended drug advocated in this life-threatening condition. Animal studies demonstrate that benzodiazepines inhibit many types of experimentally induced seizure activity, but not all. When seizures are provoked by mechanisms other than antagonism of the GABA receptor, such as theophylline-induced seizures, benzodiazepine therapy is typically unsuccessful. In treating seizure disorders, however, tolerance develops rapidly and diminishes their efficacy with time. 
Propylene glycol is the solvent used for intravenous lorazepam and diazepam, and in high doses has been implicated in the development of hyperosmolar states, lactic acidosis, and reversible acute tubular necrosis. ${ }^{46}$ An absolute dosing threshold for this complication has not been identified, but it is more commonly reported in patients receiving higher doses (lorazepam infusion $>18 \mathrm{mg} / \mathrm{h}$ ) for prolonged periods. Calculation of the osmolar gap can be used as a surrogate for serum propylene glycol concentrations. This should be monitored closely in patients receiving high doses, with an osmolar gap $>10$ suggestive of potentially toxic propylene glycol concentrations. ${ }^{47}$

Other side effects of these agents include headache, nausea or vomiting, vertigo, confusion, excessive somnolence to obtundation, respiratory depression, hypotension, hypotonia/loss of reflexes, or muscular weakness. ${ }^{36}$

\section{DRUG-DRUG INTERACTIONS}

Both diazepam and midazolam are susceptible to numerous drug interactions, as they are metabolized by the cytochrome P450 family of enzymes. Inducers of the P450 system (e.g., rifampin, carbamazepine, phenytoin, and phenobarbital) may enhance clearance of these agents, whereas inhibitors (e.g., macrolides, azole antifungals, and nondihydropyridine calcium channel blockers) may inhibit clearance. In contrast, lorazepam is prone to very few drug interactions, as it is metabolized by glucuronidation.

\section{DOSAGE RECOMMENDATIONS}

Diazepam For sedation, initial doses of 1 to $2 \mathrm{mg} \mathrm{IV}$ every 10 to 20 minutes are recommended, incrementally increasing up to $5 \mathrm{mg}$ per dose. The short duration of action limits this drug to brief sedation (for invasive procedures, etc.) or as an attempt to induce sleep. If multiple, large doses or continuous IV infusion are used, the possibility of prolonged sedation must be considered owing to its previously stated pharmacokinetic properties.

Lorazepam For sedation, 0.25 to $0.5 \mathrm{mg}$ IV every 2 to 4 hours is usually sufficient, and a 1 to $2 \mathrm{mg}$ IV bolus will often provide moderately deep sedation for 4 to 8 hours. In acute withdrawal syndromes, higher dosing is often required, but provisions for respiratory support must be made available, especially if other sedatives are being used in conjunction.

Midazolam Administer 0.5 to $2 \mathrm{mg}$ IV every 5 to 10 minutes as needed. This drug can also be administered IM $(0.07 \mathrm{mg} / \mathrm{kg})$ in contrast to diazepam where its propylene glycol based mixture may cause myonecrosis. Maintenance infusions may be started at 0.02 to $0.1 \mathrm{mg} / \mathrm{kg} / \mathrm{h}$ ( 1 to $7 \mathrm{mg} / \mathrm{h}$ ) and titrated to the target sedation score.

\section{Alpha-2 Agonists}

The two agents now in use in the ICU setting for the management of anxiety and agitation are clonidine and dexmedetomidine. Clonidine has long been used as an adjunct to general neuraxial ${ }^{48}$ and regional anesthe$\mathrm{sia}^{49}$ due to its sedative and analgesic properties, but its cardiovascular depressant effects limit its utility when combined with most other agents. The more recent approval of dexmedetomidine in the United States for the postoperative and intensive care unit settings has shown promise as an alternative to traditional sedatives, as it reduces the discomfort of mechanical ventilation while permitting rapid patient arousability for neurological examination. ${ }^{48}$ Neither clonidine nor dexmedetomidine alone are capable of inducing general anesthesia, but both agents markedly enhance the efficacy of inhalational anesthetics as well as opioids, decreasing the requirements for these other substances. ${ }^{50}$

\section{MECHANISM OF ACTION}

Both clonidine and dexmedetomidine are selective $\alpha_{2}$ adrenergic receptor agonists. Dexmedetomidine, however, is considered a "super" selective $\alpha_{2}$-agonist -8 to 10 times more avid binding to $\alpha_{2}$ receptors than clonidine. The sedative and analgesic properties of these compounds result from both presynaptic inhibition of descending noradrenergic activation of spinal neurons, as well as activation of postsynaptic $\alpha_{2}$ adrenergic receptors coupled to potassium-channel activating G-proteins. ${ }^{51}$ The summation of these effects is a decrease in sympathetic outflow from the locus coeruleus, a decrease in tonic activity in spinal motor neurons and spinothalamic pain pathways, and subsequent decreases in heart rate and blood pressure. At recommended doses, respiratory drive is not compromised.

\section{PHARMACOKINETICS AND DYNAMICS}

Clonidine is available in oral and transdermal formulations in the United States. As with the other lipophilic sedatives described previously, clonidine is rapidly distributed to the brain and spinal cord following administration. Decreases in blood pressure and heart rate may be noted within 30 to 60 minutes following oral dosing, although peak effects are not seen for 2 to 4 hours. The half-life varies between 12 to 16 hours in healthy individuals, but may be prolonged to 41 hours in patients with impaired renal function. Only $\sim 5 \%$ of plasma clonidine is removed by hemodialysis. Approximately $50 \%$ of plasma clonidine is cleared by hepatic metabolism, with the remainder of the drug eliminated unchanged in urine. Clonidine is moderately bound to serum proteins (20 to 40\%), and may compete with other substances for these binding sites.

Although the initial action of oral doses of clonidine may be relatively rapid, there may remain 
undesirable effects on heart rate and blood pressure for several days after initiation of drug therapy. ${ }^{52}$ As the time of onset for transdermal clonidine is 24 to 72 hours, this system is not useful as a sedative agent. However, transdermal clonidine may be useful in the setting of alcohol or drug withdrawal in ICU patients, or as an adjunct for reduction of sympathetic hyperactivity in severe TBI patients.

Dexmedetomidine is only given as an IV infusion, and is rapidly distributed to the brain with an equilibrium half-life of 6 to 9 minutes. The elimination half-life is 2 hours in healthy volunteers, but due to extensive metabolism by the liver this may increase to 7.5 hours in individuals with hepatic insufficiency. Due to its relatively short half-life, dexmedetomidine is easily titrated. Excretion of dexmedetomidine is primarily through the kidney as inactive methyl- and glucuronide-conjugates.

\section{RATIONALE FOR ICU USE AND ADVERSE REACTIONS}

A potential advantage of clonidine and dexmedetomidine as sedative agents compared with current popular classes of drugs, particularly propofol, benzodiazepines, and narcotics, is the nominal effect on reduction of level of arousal. Experience suggests that these agents may induce effective degrees of sedation without concomitant loss of attentive behavior and cognition following low levels of auditory or tactile stimulation. Thus, neurological assessment may be preserved while achieving the goal of a nonagitated or anxious patient. Additionally, the combination of both sedative/anxiolytic and analgesic action of clonidine and dexmedetomidine may permit single drug use for both sedation and modest pain control during the postoperative and medical ICU period in select patients.

From an intraoperative perspective, dexmedetomidine has been effectively used as a sedative for both awake craniotomy and sedation cases. Some evidence suggests prolonged cognitive deficits may persist beyond the sedative action of the drug. In the ICU, this agent has recently been demonstrated to possess advantageous characteristics for sedation in the critically ill. ${ }^{53-55}$ As in the operating arena, the ability to easily arouse patients appears to be a distinctive quality.

The most common undesirable effects of clonidine include dry mouth, bradycardia, hypotension, lightheadedness, and anxiety. Acute withdrawal of chronic clonidine administration may lead to rebound hypertension, and possible subsequent stroke or cerebral hemorrhage; dosage should thus be tapered off after prolonged use. Like clonidine, dexmedetomidine has been reported to cause hypotension and bradycardia, but to a lesser degree, and this is more commonly associated with the initial bolus dose. Treatment is supportive, with decrease or discontinuation of the infusion, IV fluids, and rarely pressors or vagolytics. In the management of TBI patients, clonidine had no significant effects on ICP, but did impair cerebral perfusion pressure via a reduction in systemic arterial pressure. ${ }^{56}$ Similar data now exists for dexmedetomidine. ${ }^{57}$ In a study of 39 neurosurgical patients, the mean CPP increased while ICP decreased during sedation. Agitation was the predominant adverse reaction, whereas hypotension occurred in 10 of the 39 patients. This class of drug appears suitable for sedation in the cerebrally injured patient.

Paradoxical transient hypertension may also be observed in association with a loading dose of dexmedetomidine, and thus infusions are often begun without a bolus. Other reported adverse reactions with dexmedetomidine include nausea, vomiting, fever, dry mouth, anxiety, and atrial fibrillation, although the incidence of these side effects did not differ significantly from placebo. Rare elevation of hepatic enzymes has also been reported.

\section{DRUG-DRUG INTERACTIONS}

Due to their sedating properties, both clonidine and dexmedetomidine may exacerbate the effects of other centrally acting depressants. Additionally, hypotension and bradycardia may be worsened by concomitant administration of antihypertensive and antidysrhythmic medications. Conversely, tricyclic antidepressants combined with clonidine may produce a paradoxical increase in blood pressure. As with all of the aforementioned sedatives, caution must be exercised when combining $\alpha$ 2 agonists with multiple medications, particularly in hypovolemic or otherwise hemodynamically unstable patients. In vitro studies suggest inhibition of the cytochrome P-450 microsomal system by dexmedetomidine; however, this does not appear to have clinically significant effects on the metabolism of other substances utilizing this metabolic pathway. ${ }^{58}$

\section{DOSAGE RECOMMENDATIONS}

Frequent monitoring of blood pressure and heart rate is recommended with initiation of clonidine or dexmedetomidine therapy.

Clonidine Initial oral dosing may be started at $0.1 \mathrm{mg}$ orally every 8 to 24 hours, increasing by $0.1 \mathrm{mg} /$ day every 1 to 2 days to a maximum of $1.2 \mathrm{mg} /$ day. Transdermal clonidine is started with the $0.1 \mathrm{mg} /$ day patch, applied to hairless skin and changed every 7 days; dosage may be incrementally-increased to the 0.2 and $0.3 \mathrm{mg} /$ day patches each week.

Dexmedetomidine Use of dexmedetomidine infusions for greater than 24 hours has not been approved by the Food and Drug Administration (FDA). A loading dose may be given as $1 \mu \mathrm{g} / \mathrm{kg}$ over 10 minutes, although this is not mandatory. For sedation in the ICU, 
maintenance infusions are titrated from 0.2 to $0.7 \mu \mathrm{g} /$ $\mathrm{kg} / \mathrm{h}$ per the product labeling. More recent data suggest doses of up to $1.4 \mu \mathrm{g} / \mathrm{kg} / \mathrm{h}$, and durations for up to 30 days are safe. ${ }^{59}$ Dosage adjustment may be necessary in individuals with hepatic insufficiency.

\section{Neuroleptics/Antipsychotics}

Neuroleptics are considered the drug of choice for patients diagnosed with delirium. In addition, the lack of respiratory depression makes them potentially attractive alternatives to more conventional sedatives for unintubated patients with pulmonary compromise. Discussion shall be limited to the two agents used most commonly in the ICU and anesthesia realms, the butyrophenones, haloperidol and droperidol.

\section{MECHANISM OF ACTION}

Neuroleptics produce both therapeutic and adverse effects by blocking cerebral and peripheral (but not spinal) dopamine, adrenergic, serotonin, acetylcholine, and histamine receptors, with variable selectivity depending on the agent. These effects include sedation (tolerance develops with repeated dosing), anxiolysis, restlessness, suppression of emotional and aggressive outbursts, reduction of delusions, hallucinations, and disorganized thoughts (over repeated dosing), antiemetic properties, hypotension (varies by agent), and extrapyramidal side effects. Haloperidol and droperidol have limited anticholinergic properties compared with other neuroleptics, reducing the occurrence of blurred vision, urinary retention, and gastrointestinal hypomotility. ${ }^{60}$

\section{PHARMACOKINETICS AND DYNAMICS}

Haloperidol is highly lipophilic and plasma-protein bound. Sedative effects may be seen within minutes of IV administration. Although plasma half-life varies from 12 to 36 hours (depending on hepatic microsomal and conjugation activities), the effective half-life may be much longer (a week or more) due to accumulation in brain and other tissues with a high blood supply. The very young and very old have a reduced capacity to metabolize haloperidol and related agents. When administered IV, droperidol has a rapid onset of action (1 to 3 minutes), although peak effects may not be noted for 30 minutes. Duration of action varies from 2 to 12 hours, and elimination appears to follow more linear (first-order) kinetics even at high doses. Systemic elimination mirrors hepatic blood flow, and thus metabolism is presumably similar to that of haloperidol.

Haloperidol is available for oral, IM, and IV administration. Droperidol is given IM or IV. Because of their onset within minutes of IV administration, both haloperidol and droperidol are readily titratable with initial bolus dosing. However, as metabolism and elim- ination may be highly variable, repeated dosing should be done with caution due to potential systemic accumulation.

\section{RATIONALE FOR ICU USE AND ADVERSE REACTIONS}

The major utility of the phenothiazines or butyrophenones is for the treatment of acute agitation secondary to psychosis or delirium. Their adverse effects negate the use of these agents for mild sedation. However, where appropriate, the effects can be dramatic and provide the necessary conditions to greatly enhance ICU management. Recent studies have illustrated the adverse effect of ICU delirium on patient ICU length-of-stay and mortality. ${ }^{15}$

Unfortunately, the use of these agents is replete with potential physiological and neurological complications, thereby limiting their utility in the ICU. Extrapyramidal side effects (Parkinsonism, acute and tardive dystonias, tardive dyskinesia, akathisia, and perioral tremor) may be expressed. Although less common with butyrophenones than with phenothiazine antipsychotics, such motor disturbances may still occur with both haloperidol and droperidol. Regarding possible other CNS effects, droperidol had little effect on ICP, although cerebral perfusion pressure was decreased by moderate systemic hypotension. ${ }^{61}$

Lowering of the seizure threshold has been a longstanding concern with the phenothiazines. Neuroleptics do induce slowing and synchronization (with associated increased voltage) of the EEG ${ }^{60}$ However, effects on the seizure threshold are highly variable, depending on the agent. Haloperidol and related butyrophenones (including droperidol) have unpredictable effects on seizure threshold, and although most studies suggest a low risk, these drugs should be used with caution in patients with known seizure disorders.

Other potential side effects including increased prolactin secretion, orthostatic hypotension (rare with haloperidol and droperidol), neuroleptic malignant syndrome, and jaundice (rare with butyrophenones) have all been reported for neuroleptics in general. ${ }^{60}$ Both haloperidol and droperidol can induce QT prolongation and torsades de pointes, and warnings have been issued regarding this adverse effect with even low doses of droperidol, greatly limiting the use of this agent for its perioperative sedation and antiemetic properties. ${ }^{62}$ As such, droperidol is contraindicated in patients with preexisting QT prolongation, and should be used with extreme caution in those at risk for cardiac dysrhythmias. Although chlorpromazine and other typical phenothiazine antipsychotics have been associated with hypotension, negative inotropy, and nonspecific ST and T-wave changes (including QT prolongation), significant hemodynamic side effects are rare with haloperidol and droperidol. ${ }^{60}$ Both droperidol and haloperidol may cause 
systemic hypotension via peripheral vasodilatation when given IV.

Prior to treatment with droperidol, a 12-lead electrocardiogram (EKG) should be performed to evaluate for preexistent QT prolongation that would preclude use of this medication. Continuous EKG monitoring must be performed for several hours following administration of droperidol, and appropriate treatments for hypotension, QT prolongation, and ventricular dysrhythmias must be readily available. Because of potential hypotension from IV haloperidol or droperidol, frequent blood pressure measurement should also be performed during use of these medications.

Because of the risk of ventricular dysrhythmias, droperidol should not be concurrently administered with any medications that may prolong the QT interval. ${ }^{62}$ These include, but are not limited to, antihistamines, several antibiotics, class I or III antiarrhythmics, and many antidepressants. Hypomagnesemia and hypokalemia should be avoided or treated.

\section{DRUG-DRUG INTERACTIONS}

Because of their sedative and potential autonomic effects, haloperidol and droperidol may enhance the effects of other sedative agents (including anticonvulsants). Additionally, any medications that induce the hepatic microsomal enzyme system may increase the rate at which neuroleptics are metabolized. Selective serotonin reuptake inhibitors (SSRIs) compete with neuroleptics for hepatic oxidative enzymes, and may therefore increase circulating levels of haloperidol and droperidol. ${ }^{60}$ In addition, coadministration with any agent which can prolong the QT interval may increase the likelihood of torsades de pointes, and routine EKG monitoring is necessary. As with all medications, nonspecific adverse effects including anaphylaxis, laryngospasm, and bronchospasm have been reported.

\section{DOSAGE RECOMMENDATIONS}

Haloperidol For sedation, initial IV doses of 0.5 to $5 \mathrm{mg}$ may be used. Dosage should be low in the elderly and in those with hemodynamic instability or high risk of seizures. The half-life is 12 to 36 hours, but active metabolites may remain for a much longer period.

Droperidol For sedation in the setting of agitation, a starting dosage of $0.625 \mathrm{mg}$ to a maximum of $2.5 \mathrm{mg} \mathrm{IV}$ is recommended. Additional dosages should not exceed 0.625 to $1.25 \mathrm{mg}$ every 2 to 4 hours.

\section{Propofol}

Propofol, an ultra-short-acting alkylphenol, is an agent that has been extensively used both as a sedative agent in critically ill patients as well as a general anesthetic. Although structurally distinct, its clinical action and effects on cerebral activity and intracranial dynamics are very similar to the short-acting barbiturates, such as thiopental. However, its extremely high rate of clearance results in even shorter duration of action, especially noted following prolonged infusions, as compared with barbiturates. ${ }^{5}$ This novel compound has other advantages over the older class of drugs, including less emetic properties than barbiturates, as well as being a mood enhancer rather than frank depressant. However, reports of fatal metabolic acidosis and myocardial failure following long-term administration of propofol (especially in children) have tempered enthusiasm for this agent. ${ }^{63}$

\section{MECHANISM OF ACTION}

A GABAergic mechanism of action has been suggested for propofol based on both in vivo and in vitro binding studies, ${ }^{64}$ with evidence that propofol may directly bind to $\mathrm{GABA}_{\mathrm{a}}$ receptors and activate inhibitory chloride channels in the absence of GABA. Other studies suggest a nonspecific, but structurally dependent effect on neuronal plasma membrane fluidity. ${ }^{65}$ The specific mechanism(s) of action of propofol thus remains unclear.

\section{PHARMACOKINETICS AND DYNAMICS}

Similar to thiopental in its lipophilicity, propofol is rapidly distributed to the brain following IV administration. It has a distribution half-life of 1 to 8 minutes, substantially shorter than most sedative agents with an equally rapid recovery following redistribution to other less perfused tissues. ${ }^{5,66}$ Repeated or continuous dosing of propofol is cleared far more rapidly than thiopental. This is a result of a high degree of clearance, calculated to approach or exceed 1.5 to $2 \mathrm{~L} /$ minute, which is greater than that of hepatic blood flow. Such kinetics suggests extrahepatic sites of metabolism. This brief elimination time allows for more rapid recovery following cessation of sedative infusions. Propofol is also highly plasma protein bound, with free circulating levels increased in hypoalbuminic states.

Propofol is administered IV at a premixed concentration of $10 \mathrm{mg} / \mathrm{mL}(1 \%)$. For the purposes of ICU sedation it is given as a continuous infusion; however, it may also be given as boluses for other indications. Due to its insolubility in water, propofol is suspended as an emulsion in a mixture of soybean oil, glycerol, and egg phospholipids, leaving it susceptible to bacterial contamination. Despite the presence of ethylenediaminetetraacetate (EDTA) as a bacteriostatic agent, propofol must be handled in an aseptic manner, and unused solutions discarded within 6 to 12 hours after a sterile seal is broken. 
For continuous sedation in the ICU, the dose ranges from 5 to $80 \mu \mathrm{g} / \mathrm{kg} /$ minute. For other ICU indications (burst suppression EEG for refractory status epilepticus or refractory intracranial hypertension), general anesthesia doses such as 100 to $300 \mu \mathrm{g} / \mathrm{kg} /$ minute may be required.

\section{RATIONALE FOR ICU USE AND ADVERSE REACTIONS}

The major utility of propofol in an ICU setting is its ultra-short duration of action, making it thus readily titratable and rapidly eliminated. It produces a stereotypic suppression of EEG activity similar to the barbiturates, from increasing theta and delta to a flat EEG pattern during deep general anesthesia. Thus, this drug can also be used to suppress seizure activity at high doses. As a sedative-hypnotic, propofol provides sedation devoid of any analgesia. Owing to a dose-dependent effect on cerebral metabolism, propofol also has a niche in the control of intracranial hypertension.

Propofol is by no means an ideal drug, especially in the ICU. As mentioned, no analgesic action is provided, so this sedative should not be used alone during sedation for painful maneuvers. Propofol may cause hypotension due to both vasodilation and a negative inotropic effect, and impairs the cardioaccelerator response to decreased blood pressure. This hypotension may be especially pronounced in patients with reduced cardiac output, hypovolemia, on other cardiodepressant medications, or the elderly. When used as a sedative for severe TBI patients, propofol may impair cerebral perfusion even as it induces a fall in ICP. Dose-dependent respiratory depression is a predictable result of the drug, and propofol should be used only in the setting of a controlled airway or in the continuous presence of experienced critical care or anesthesia personnel. During bolus or continuous infusions of propofol, frequent or continuous monitoring of pulse-oximetry, respiratory rate and depth of respiration, and blood pressure is recommended. Invasive monitoring of blood pressure and cardiac output may be necessary for high-dose propofol (e.g., burst suppression EEG).

Pain on injection, which is common and due to the carrier solution, may be lessened by administration through central or larger veins, or pretreatment of peripheral injection sites with intravenous lidocaine (0.5 to $1 \mathrm{mg} / \mathrm{kg}$ ). Far less common are potential anaphylactoid reactions with propofol. ${ }^{67}$ Usually, an immunological reaction is due not to the parent compound, but to the emulsion which contains egg and soy product. Thus, administration of propofol is contraindicated in individuals who have had a severe allergic reaction to these food substances. Given the lipid vehicle of propofol, hypertriglyceridemia may occur, particularly at higher doses or prolonged duration.

Although the side-effect profile for propofol is far more favorable than that for barbiturates, a syndrome of metabolic acidosis, hyperkalemia, rhabdomyolysis, and hypoxia has been described in children ${ }^{63}$ and more recently in adults ${ }^{67}$ receiving prolonged infusions of propofol. The etiology of this syndrome is unclear, and in the majority of reported cases the affected individuals were critically ill and on multiple other medications that may have initiated the metabolic disarray. Nonetheless, careful monitoring of electrolytes, lactic acid, creatine kinase, and triglycerides is highly recommended in patients receiving doses $>80 \mu \mathrm{g} / \mathrm{kg} /$ minute for prolonged periods.

\section{DRUG-DRUG INTERACTIONS}

As with nearly all of the preceding sedatives, propofol may potentiate the sedative and cardiovascular effects of alcohol, opioids, benzodiazepines, barbiturates, other general anesthetics, antihypertensives, and antiarrhythmics. Propofol does not appear to alter the metabolism, elimination, or plasma protein binding of other drugs. Because of the scattered reports of rhabdomyolysis, metabolic acidosis, and myocardial failure following prolonged infusions of propofol, this agent should be used with caution when combined with other medications with similar potential. In addition, the high lipid content of propofol should be kept in mind when prescribing nutrition regimens, as the lipid vehicle constitutes a significant source of calories $(1.1 \mathrm{kcal} / \mathrm{mL})$ from fat.

\section{SUMMARY}

Sedation of critically ill patients is common and provided as part of an optimal care plan. Neurological patients represent a particularly challenging subset given the need to balance comfort with maintenance of the neurological exam. Detailed knowledge of the available agents and patient-specific variables is necessary to strike this balance, necessitating the need for an interdisciplinary approach. Careful selection from the classes of available sedative agents is important to reduce toxicity and relieve patient anxiety, agitation, or delirium. The incorporation of appropriate sedation scales is a valuable adjunct to define depth of sedation and to assure optimal drug titration and seamless communication of the goals of therapy. Due to the individualized nature of drug response, careful selection and dosing must be performed in each patient to meet the intended sedation goal while preserving patient safety. 


\section{REFERENCES}

1. Payen JF, Chanques G, Mantz J, et al. Current practices in sedation and analgesia for mechanically ventilated critically ill patients: a prospective multicenter patient-based study. Anesthesiology 2007;106:687-695

2. Phillips DM. JCAHO pain management standards are unveiled. Joint Commission on Accreditation of Healthcare Organizations. JAMA 2000;284:2317-2318

3. Kress JP, Pohlman AS, O'Connor MF, Hall JB. Daily interruption of sedative infusions in critically ill patients undergoing mechanical ventilation. N Engl J Med 2000;342: 1471-1477

4. Hogarth DK, Hall J. Management of sedation in mechanically ventilated patients. Curr Opin Crit Care 2004;10(1): 40-46

5. Mirski MA, Muffelman B, Ulatowski JA, Hanley DF. Sedation for the critically ill neurologic patient. Crit Care Med 1995;23:2038-2053

6. Siffleet J, Young J, Nikoletti S, Shaw T. Patients' self-report of procedural pain in the intensive care unit. J Clin Nurs 2007;16:2142-2148

7. Li D, Puntillo K, Miaskowski C. A review of objective pain measures for use with critical care adult patients unable to self-report. J Pain 2008;9:2-10

8. Mateo OM, Krenzischek DA. A pilot study to assess the relationship between behavioral manifestations and selfreport of pain in postanesthesia care unit patients. J Post Anesth Nurs 1992;7:15-21

9. Payen JF, Bru O, Bosson JL, et al. Assessing pain in critically ill sedated patients by using a behavioral pain scale. Crit Care Med 2001;29:2258-2263

10. Gelinas C, Fillion L, Puntillo K, Viens C, Fortier M. Validation of the critical-care pain observation tool in adult patients. Am J Crit Care 2006;15:420-427

11. Odhner M, Wegman D, Freeland N, Steinmetz A, Ingersoll G. Assessing pain control in nonverbal critically ill adults. Dimens Crit Care Nurs 2003;22:260-267

12. Puntillo KA, Miaskowski C, Kehrle K, Stannard D, Gleeson S, Nye P. Relationship between behavioral and physiological indicators of pain, critical care patients' self-reports of pain, and opioid administration. Crit Care Med 1997;25:11591166

13. Labus JS, Keefe FJ, Jensen MP. Self-reports of pain intensity and direct observations of pain behavior: When are they correlated? Pain 2003;102:109-124

14. Ely EW, Siegel MD, Inouye S. Delirium in the intensive care unit: an under-recognized syndrome of organ dysfunction. Semin Respir Crit Care Med 2001;22:115-126

15. Thomason JW, Shintani A, Peterson JF, et al. Intensive care delirium is an independent predictor of longer hospital stay: a prospective analysis of 261 non-ventilated patients. Crit Care 2005;9:R375-R381

16. Ramsay MA, Savege TM, Simpson BR, Goodwin R. Controlled sedation with alphaxalone-alphadolone. BMJ 1974;2:656-659

17. Riker RR, Picard JT, Fraser GL. Prospective evaluation of the Sedation-Agitation Scale for adult critically ill patients. Crit Care Med 1999;27:1325-1329

18. Riker RR, Fraser GL, Simmons LE, Wilkins ML. Validating the Sedation-Agitation Scale with the Bispectral Index and Visual Analog Scale in adult ICU patients after cardiac surgery. Intensive Care Med 2001;27:853-858
19. Devlin JW, Boleski G, Mlynarek M, et al. Motor Activity Assessment Scale: a valid and reasonable sedation scale for use with mechanically ventilated patients in an adult surgical intensive care unit. Crit Care Med 1999;27: 1271-1275

20. Sessler CN, Gosnell MS, Grapp MJ, et al. The Richmond Agitation-Sedation Scale. Validity and reliability in adult intensive care unit patients. Am J Respir Crit Care Med 2002;166:1338-1344

21. De Jonghe B, Cook D, Griffith L, et al. Adaptation to the Intensive Care Environment (ATICE): development and validation of a new sedation assessment instrument. Crit Care Med 2003;31:2344-2354

22. Avripas MB, Smythe MA, Carr A, Begle RL, Johnson MH, Erb DR. Development of an intensive care unit bedside sedation scale. Ann Pharmacother 2001;35:262-263

23. Ely EW, Truman B, Shintani A, et al. Monitoring sedation status over time in ICU patients: reliability and validity of the Richmond Agitation-Sedation Scale (RASS). JAMA 2003; 289:2983-2991

24. de Lemos J, Tweeddale M, Chittock D. Measuring quality of sedation in adult mechanically ventilated critically ill patients: the Vancouver Interaction and Calmness Scale. J Clin Epidemiol 2000;53:908-919

25. Weinert C, McFarland L. The state of intubated ICU patients. Development of a two-dimensional sedation rating scale for critically ill adults. Chest 2004;126:1883-1890

26. Jacobi J, Fraser GL, Coursin DB, et al. Clinical practice guidelines for the sustained use of sedatives and analgesics in the critically ill adult. Crit Care Med 2002;30:119-141

27. Park KS, Hur EJ, Han KW, Kil HY, Han TH. Bispectral index does not correlate with observer assessment of alertness and sedation scores during $0.5 \%$ bupivacaine epidural anesthesia with nitrous oxide sedation. Anesth Analg 2006; 103:385-389

28. Sackey PV, Radell PJ, Granath F, Martling CR. Bispectral index as a predictor of sedation depth during isoflurane or midazolam sedation in ICU patients. Anaesth Intensive Care 2007;35:348-356

29. Tukenmez B, Memis D, Pamukcu Z. The addition of haloperidol, propofol, or midazolam to sufentanil for intravenous sedation in the intensive care unit using bispectral index. J Opioid Manag 2008;4:34-40

30. Gutstein HB, Akil H. Opioid analgesics. In: Hardman JG, Limbird LE, eds. Goodman and Gilman's The Pharmacological Basis of Therapeutics. 10th ed. New York: McGrawHill; 2001:569-619

31. Pan YX, Xu J, Bolan E, Moskowitz HS, Xu M, Pasternak GW. Identification of four novel exon 5 splice variants of the mouse mu-opioid receptor gene: functional consequences of C-terminal splicing. Mol Pharmacol 2005;68:866-875

32. Muellejans B, López A, Cross MH, Bonome C, Morrison L, Kirkham AJ. Remifentanil versus fentanyl for analgesia based sedation to provide patient comfort in the intensive care unit: a randomized, double-blind controlled trial. Crit Care 2004; 8:R1-R11

33. Rao TLK, Mummaneni N, El-Etr AA. Convulsions: an unusual response to intravenous fentanyl administration. Anesth Analg 1982;61:1020-1021

34. Murkin JM, Moldenhauer CC, Hug CC, et al. Absence of seizures during induction of anesthesia with high-dose fentanyl. Anesth Analg 1984;63:489-494 
35. De Conno F, Caraceni A, Martini C, et al. Hyperalgesia and myoclonus with intrathecal infusion of high-dose morphine. Pain 1991;47:337-339

36. Flacke JW, Flacke WE, Bloor BC, Van Etten AP, Kripke BJ. Histamine release by four narcotics: a double-blind study in humans. Anesth Analg 1987;66:723-730

37. Charney DS, Mihic SJ, Harris RA. Hypnotics and sedatives. In: Hardman JG, Limbird LE, eds. Goodman and Gilman's The Pharmacological Basis of Therapeutics. 10th ed. New York: McGraw-Hill; 2001:399-427

38. Greenblatt DJ, Divoll M, Abernathy DR, et al. Clinical pharmacokinetics of the newer benzodiazepines. Clin Pharmacokinet 1983;8:233-252

39. Hoffman EJ, Warren EW. Flumazenil: a benzodiazepine antagonist. Clin Pharm 1993;12:641-656

40. Sanchez-Izquierdo-Riera JA, Caballero-Cubedo RE, PerezVela JL, Ambros-Checa A, Cantalapiedra-Santiago JA, Alted-Lopez E. Propofol versus midazolam: safety and efficacy for sedating the severe trauma patient. Anesth Analg 1998;86:1219-1224

41. Forster A, Juge O, Morel D. Effects of midazolam on cerebral hemodynamics and cerebral vasomotor responsiveness to carbon dioxide. J Cereb Blood Flow Metab 1983;3: 246-249

42. Ely EW, Inouye SK, Bernard GR, et al. Delirium in mechanically ventilated patients: validity and reliability of the confusion assessment method for the intensive care unit (CAM-ICU). JAMA 2001;286:2703-2710

43. Bergeron N, Dubois MJ, Dumont M, Dial S, Skrobik Y. Intensive Care Delirium Screening Checklist: evaluation of a new screening tool. Intensive Care Med 2001;27:859864

44. Pandharipande P, Jackson J, Ely EW. Delirium: acute cognitive dysfunction in the critically ill. Curr Opin Crit Care 2005;11:360-368

45. Claassen J, Hirsch LJ, Emerson RG, Bates JE, Thompson TB, Mayer SA. Continuous EEG monitoring and midazolam infusion for refractory nonconvulsive status epilepticus. Neurology 2001;57:1036-1042

46. Neale BW, Mesler EL, Young M, Rebuck JA, Weise WJ. Propylene glycol-induced lactic acidosis in a patient with normal renal function: a proposed mechanism and monitoring recommendations. Ann Pharmacother 2005;39:1732-1736

47. Barnes BJ, Gerst C, Terrell AR, Mullins ME. Osmol gap as a surrogate marker for serum propylene glycol concentrations in patients receiving lorazepam for sedation. Pharmacotherapy $2006 ; 26: 23-33$

48. Dobrydnjov I, Axelsson K, Samarutel J, Holmstrom B. Postoperative pain relief following intrathecal bupivacaine combined with intrathecal or oral clonidine. Acta Anaesthesiol Scand 2002;46:806-814

49. Iskandar H, Guillaume E, Dixmerias F, et al. The enhancement of sensory blockade by clonidine selectively added to mepivacaine after midhumeral block. Anesth Analg 2001; 93:771-775

50. Venn RM, Grounds RM. Comparison between dexmedetomidine and propofol for sedation in the intensive care unit: patient and clinician perceptions. Br J Anaesth 2001;87:684690

51. Khan ZP, Munday IT, Jones RM, Thornton C, Mant TG, Amin D. Effects of dexmedetomidine on isoflurane requirements in healthy volunteers. 1: Pharmacodynamic and pharmacokinetic interactions. Br J Anaesth 1999;83:372380

52. Tulen JH, van de Wetering BJ, Kruijk MP, et al. Cardiovascular, neuroendocrine, and sedative responses to four graded doses of clonidine in a placebo-controlled study. Biol Psychiatry 1992;32:485-500

53. Pandharipande PP, Pun BT, Herr DL, et al. Effect of sedation with dexmedetomidine vs lorazepam on acute brain dysfunction in mechanically ventilated patients: the MENDS randomized controlled trial. JAMA 2007;298: 2644-2653

54. Szumita PM, Baroletti SA, Anger KE, Wechsler ME. Sedation and analgesia in the intensive care unit: evaluating the role of dexmedetomidine. Am J Health Syst Pharm 2007;64:37-44

55. Elbaradie S, El Mahalawy FH, Solyman AH. Dexmedetomidine vs. propofol for short-term sedation of postoperative mechanically ventilated patients. J Egypt Natl Canc Inst 2004;16:153-158

56. ter Minassian A, Beydon L, Decq P, Bonnet F. Changes in cerebral hemodynamics after a single dose of clonidine in severely head-injured patients. Anesth Analg 1997;84:127132

57. Aryan HE, Box KW, Ibrahim D, Desiraju U, Ames CP. Safety and efficacy of dexmedetomidine in neurosurgical patients. Brain Inj 2006;20:791-798

58. Talke P, Richardson CA, Scheinin M, Fisher DM. Postoperative pharmacokinetics and sympatholytic effects of dexmedetomidine. Anesth Analg 1997;85:1136-1142

59. Riker R. The Precedex ICU Long Term Sedation Trial Results. Paper presented at: the Society of Critical Care Medicine 37th Critical Care Congress; February 2-6, 2008; Honolulu, HI

60. Baldessarini RJ, Tarazi FI. Drugs and the treatment of psychiatric disorders: psychosis and mania. In: Hardman JG, Limbird LE, eds. Goodman and Gilman's The Pharmacological Basis of Therapeutics. 10th ed. New York: McGrawHill; 2001:485-520

61. Misfeldt BB, Jorgensen PB, Spotoft H, Ronde F. The effects of droperidol and fentanyl on intracranial pressure and cerebral perfusion pressure in neurosurgical patients. $\mathrm{Br} \mathrm{J}$ Anaesth 1976;48:963-968

62. Lischke V, Behne M, Doelken P, Schledt U, Probst S, Vettermann J. Droperidol causes a dose-dependent prolongation of the QT interval. Anesth Analg 1994;79:983986

63. Vasile B, Rasulo F, Candiani A, Latronico N. The pathophysiology of propofol infusion syndrome: a simple name for a complex syndrome. Intensive Care Med 2003; 29:1417-1425

64. Alkire MT, Haier RJ. Correlating in vivo anaesthetic effects with ex vivo receptor density data supports a GABAergic mechanism of action for propofol, but not for isoflurane. Br J Anaesth 2001;86:618-626

65. Tsuchiya H. Structure-specific membrane-fluidizing effect of propofol. Clin Exp Pharmacol Physiol 2001;28:292-299

66. Greenblatt DJ. Intravenous anesthetic agents. Pharmacokinetic-pharmacodynamic relationships. Clin Pharmacokinet 1981;6:89-105

67. Perrier ND, Baerga-Varela Y, Murray MJ. Death related to propofol use in an adult patient. Crit Care Med 2000;28: 3071-3074 


\section{APPENDIX: SPECIFIC SEDATION SCALES \\ USED IN THE INTENSIVE CARE UNIT}

\section{Motor Activity Assessment Scale}

\begin{tabular}{|c|c|c|}
\hline Score & Description & Definition \\
\hline 0 & Unresponsive & Does not move with noxious stimulus* \\
\hline 1 & Responsive only to noxious stimuli & $\begin{array}{l}\text { Opens eyes OR raises eyebrows OR turns head toward stimulus OR moves limbs } \\
\text { with noxious stimulus* }\end{array}$ \\
\hline 2 & Responsive to touch OR name & $\begin{array}{l}\text { Opens eyes OR raises eyebrows OR turns head toward stimulus OR moves limbs } \\
\text { when touched or name is loudly spoken }\end{array}$ \\
\hline 3 & Calm and cooperative & $\begin{array}{l}\text { No external stimulus is required to elicit movement AND patient is adjusting } \\
\text { sheets or clothes purposefully and follows commands }\end{array}$ \\
\hline 4 & Restless and cooperative & $\begin{array}{l}\text { No external stimulus is required to elicit movement AND patient is picking at } \\
\text { sheets or tubes OR uncovering self and follows commands }\end{array}$ \\
\hline 5 & Agitated & $\begin{array}{l}\text { No external stimulus is required to elicit movement AND attempting to sit up OR } \\
\text { moves limbs out of bed AND does not consistently follow commands } \\
\text { (e.g., will lie down when asked but soon reverts back to attempts to sit up } \\
\text { or move limbs out of bed) }\end{array}$ \\
\hline 6 & $\begin{array}{l}\text { Dangerously agitated, } \\
\text { uncooperative }\end{array}$ & $\begin{array}{l}\text { No external stimulus is required to elicit movement AND patient is pulling at } \\
\text { tubes or catheters OR thrashing side to side OR striking at staff OR trying to } \\
\text { climb out of bed AND does not calm down when asked }\end{array}$ \\
\hline
\end{tabular}

*Noxious stimulus, suctioning, OR 5 seconds of vigorous orbital, sternal, or nail bed pressure. Adapted from Devlin et al. ${ }^{19}$

Riker Sedation-Agitation Scale (SAS)

\begin{tabular}{lll}
\hline Score & Category & Description \\
\hline 7 & Dangerous agitation & $\begin{array}{r}\text { Pulling at endotracheal tube, trying to remove catheters, climbing over bedrail, striking at staff, } \\
\text { thrashing side-to-side } \\
\text { Does not calm despite frequent verbal reminding of limits, requires physical restraints, biting } \\
\text { endotracheal tube }\end{array}$ \\
5 & Very agitated & Anxious or mildly agitated, attempting to sit up, calms down on verbal instructions \\
4 & Agitated & Calm, easily aroused, follows commands \\
3 & Sedated & Difficult to arouse, awakens to verbal stimuli or gentle shaking but drifts off again, follows \\
2 & Very sedated & Arouses to physical stimuli but does not communicate or follow commands, may move \\
1 & Unarousable & spontaneously
\end{tabular}

Adapted from Riker et al. ${ }^{17}$

Richmond Agitation-Sedation Scale

\begin{tabular}{lll}
\hline Score & Term & Description \\
\hline+4 & Combative & Overtly combative or violent; immediate danger to staff \\
+3 & Very agitated & Pulls on or removes tube(s) or catheter(s) or has aggressive behavior toward staff \\
+2 & Agitated & Frequent nonpurposeful movement or patient-ventilator dyssynchrony \\
+1 & Restless & Anxious or apprehensive, but movements not aggressive or vigorous \\
0 & Alert and calm & \\
-1 & Drowsy & Not fully alert, but has sustained ( $>10$ seconds) awakening, with eye contact, to voice \\
-2 & Light sedation & Briefly ( $<10$ seconds) awakens with eye contact to voice \\
-3 & Moderate sedation & Any movement (but no eye contact) to voice \\
-4 & Deep sedation & No response to voice, but any movement to physical stimulation \\
-5 & Unarousable & No response to voice or physical stimulation \\
\hline
\end{tabular}

Adapted from Sessler et al. ${ }^{20}$ 


\section{AVRIPAS: Revised Sedation Scale}

\begin{tabular}{|c|c|}
\hline Agitation & Alertness \\
\hline 1. Unresponsive to command/physical stimulation & 1. Difficult to arouse, eyes remain closed \\
\hline 2. Appropriate response to physical stimuli/calm & 2. Mostly sleeping, eyes closed \\
\hline 3. Mild anxiety/delirium/agitation (calms easily) & 3. Dozing intermittently, arouses easily \\
\hline 4. Moderate anxiety/delirium/agitation & 4. Awake, calm \\
\hline 5. Severe anxiety/delirium/agitation & 5. Wide awake, hyperalert \\
\hline \multicolumn{2}{|l|}{ 1. Intubated, no spontaneous effort } \\
\hline \multicolumn{2}{|l|}{ 2. Respirations even, synchronized with ventilator } \\
\hline \multicolumn{2}{|l|}{ 3. Mild dyspnea/tachypnea, occasional asynchrony } \\
\hline \multicolumn{2}{|l|}{ 4. Frequent dyspnea/tachypnea, ventilator asynchrony } \\
\hline \multicolumn{2}{|l|}{ 5. Sustained, severe dyspnea/tachypnea } \\
\hline Patient Classification & Sedation Goal \\
\hline Acutely ill (weaning not a goal) & $5-9$ \\
\hline Ventilated patient being weaned & $7-10$ \\
\hline Chronic ventilated patient (weaning not a goal) & $6-9$ \\
\hline Nonventilated patient & $7-9$ \\
\hline
\end{tabular}

Adapted from Avripas et al. ${ }^{22}$

\section{Adaptation to the Intensive Care Environment (ATICE) Instrument Scale}

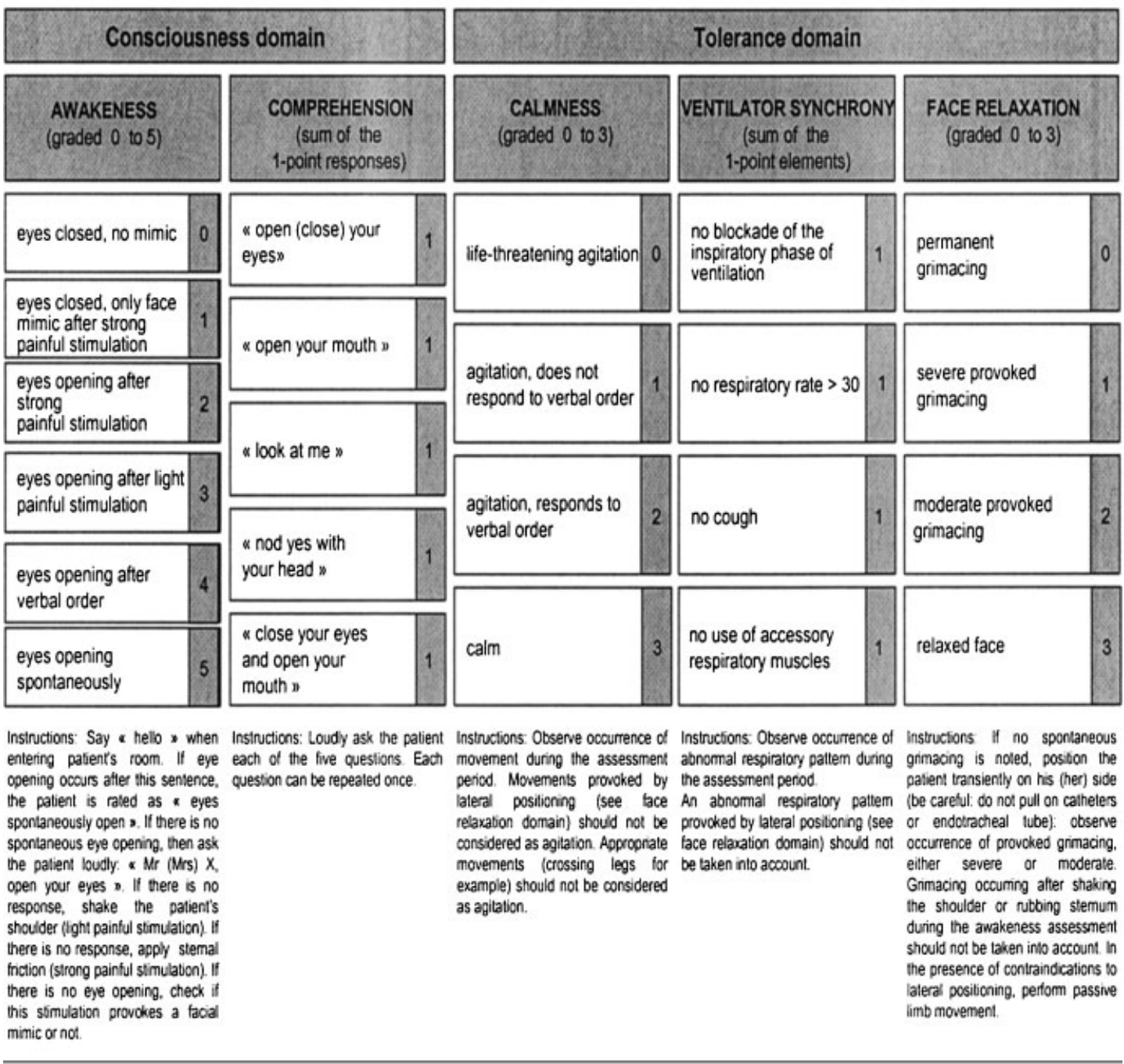

Adapted from de Jonghe et al. ${ }^{21}$ 


\section{Procedure for Scoring the}

Minnesota Sedation Assessment Tool (MSAT)

1. Record the highest level of unstimulated spontaneous motor activity observed in the last 10 minutes.

2. Walk to the right shoulder and observe eye opening and/or tracking.

3. If no eye opening, call first name and "open your eyes!"

4. If no eye opening yet, shake right shoulder firmly, call first name and "open your eyes!"

5. Choose the arousal scale category appropriate for the patient's response to procedures 2 to 4 .

6. Judge the current quality of the sedation therapy as "adequate," "oversedated," or "undersedated." Use any clinical information available to you in addition to the scale levels.

\section{MOTOR ACTIVITY SCALE}

- Movement of central muscle group (back or abdominal muscles)

- Movement of proximal limbs (hip or shoulder)

- Movement of distal limbs or head and neck muscles

- No spontaneous movement

Note: Disregard respiratory efforts, cough, swallowing, eye movement, or isolated tiny muscle contractions.

\section{AROUSAL SCALE}

- Eyes open spontaneously with tracking

- Eyes open spontaneously, but not tracking

- Eyes closed, but open to sound of voice

- Eyes closed, but open to shoulder shake plus sound of voice

- Eyes stay closed, but other patient movement observed in response to stimulation

- Eyes stay closed and no patient movement observed in response to stimulation

Adapted from Weinert and McFarland. ${ }^{25}$

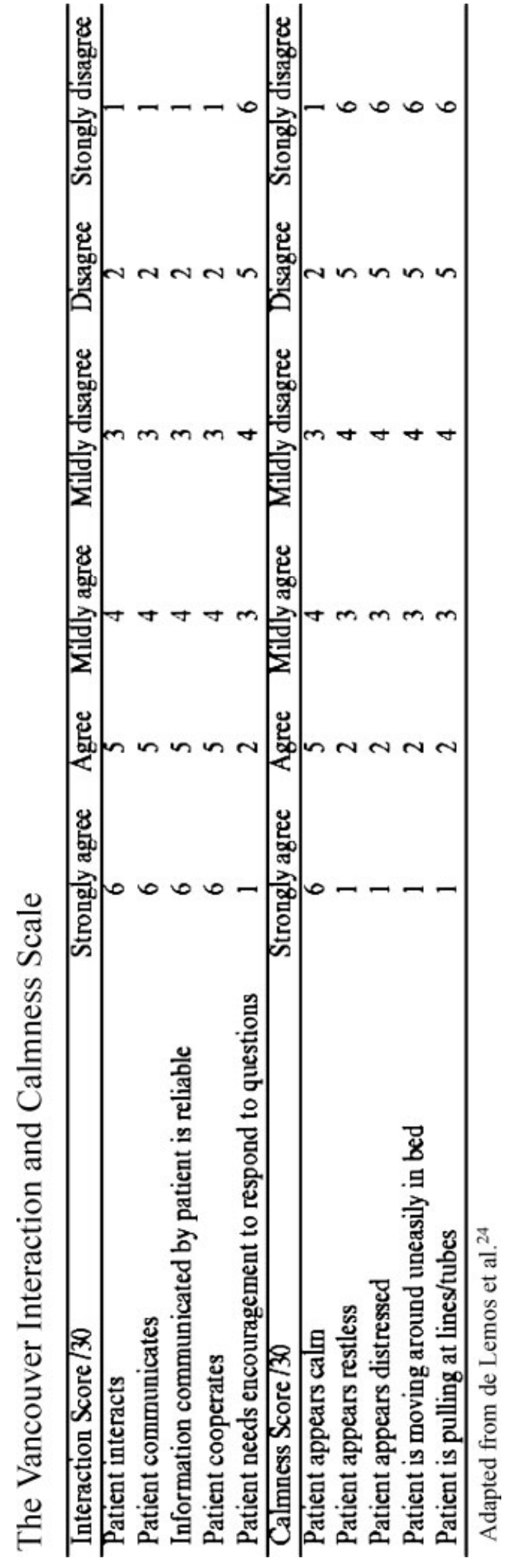

